\title{
Potências monstruosas e ambiguidades sexuais: o caso de Herculine Barbin
}

\author{
Monstrous potencies and sexual ambiguities: the case of Herculine Barbin
}

\author{
Izabel Rizzi Mação; Davis Moreira Alvim; Julio César Bentivoglio
}

Universidade Federal do Espírito Santo; Instituto Federal de Educação, Ciência e Tecnologia do Espírito Santo

\section{RESUMO:}

Propõe-se uma abordagem genealógica do problema das ambiguidades sexuais, atentando para as relações de poder/saber que vão, ao longo dos séculos XVIII e XIX, conectando a imagem do monstro ao corpo sexualmente ambíguo. Também recorremos ao conceito de abjeto, indicando sua funcionalidade na formação do sujeito e na instalação da diferença sexual enquanto norma. Ao mesmo tempo, seguimos por pequenas ondulações, tensões e desorientações na composição do sistema sexo/gênero, notadamente aquelas sugeridas no manuscrito "Minhas Memórias", de Herculine Barbin - uma pessoa intersexual que viveu e escreveu no contexto do século XIX europeu. Com Herculine, avançamos por zonas inóspitas, nas quais nos esbarramos com as potências do monstruoso e do abjeto para desnaturalizar a noção de verdadeiro sexo e, também, a própria concepção ontológica do humano.

Palavras-chave: diferença de sexo; natureza humana; corpo

\begin{abstract}
:
A genealogical approach to the problem of sexual ambiguities is proposed, paying attention to the relations of power/knowledge that, throughout the 18th and 19th centuries, connect the image of the monster to the sexually ambiguous body. We also resort to abject concept, indicating its functionality in the formation of the subject and in the installation of sexual difference as a normative aspect. At the same time, we follow small undulations, tensions and disorientations in the sex/gender system composition, notably those suggested in the manuscript "My Memories" (Minhas Memórias), written by Herculine Barbin, an intersexual person who lived and wrote in the context of 19th century Europe. With Herculine, we travel inhospitable zones, where we encounter the potencies of the monstrous and the abject to denature the notion of true sex, as well as the human ontological conception itself.
\end{abstract}

Key-words: sex difference; human nature; body

DOI: 10.12957/mnemosine.2020.57673

\section{Qualquer Coisa Que Se Mova}

As hienas, dizem, mudam de sexo periodicamente: o macho se torna fêmea e vice-versa. Ora, como uma hiena repreendia uma raposa por rejeitar sua corte, a raposa respondeu: "Não é por mim, mas por tua natureza, pois não posso saber se me tomarás como um amante ou como uma amante". Cuidado com o homem ambíguo.

( $A$ hiena e a raposa, Esopo, século V a.C.) 
As noções de natural e natureza tornaram-se imperativos importantes nas buscas por despatologizar ou combater o preconceito contra as sexualidades e as identidades de gênero dissidentes. Para reforçar que uma sexualidade é normal - ou natural - procuraram-se, por exemplo, semelhanças no comportamento sexual de gorilas, leões, golfinhos e plantas; enfim, na natureza não-humana tomada como sinônimo de normalidade. O mundo dos não-humanos também nomeia sexualidades ou comportamentos sexuais de modo mais geral: homens gays denominam a si mesmos como viados, enquanto certas mulheres lésbicas se identificam como sapas; um homem que fica com muitas mulheres pode ser chamado garanhão, e uma mulher que fica com muitas pessoas seria uma piranha.

Nesse universo de referentes animais utilizados para tratar do comportamento sexual, algumas figuras parecem deslocadas, como se não houvesse um lugar para as encaixar. Em fábulas, mitos ou histórias, elas surgem sob o signo da advertência: são aqueles e aquelas dos quais devemos nos aproximar com cautela, pois sua natureza seria obscura e inconstante. As hienas, conforme nos alerta Esopo na fábula "A Hiena e a Raposa", aparecem entre esses seres duvidosos, cuja natureza feminina ou masculina não pode ser identificada à primeira vista Aparentadas a tantas outras existências confusas, os andróginos, os hermafroditas ${ }^{1}$ e os bissexuais, tal qual as hienas, são tratados como parte dessas criaturas sobre as quais nossa única certeza é a de sua temerária ambivalência. Suas histórias são marcadas por uma aversão ou por uma espécie de lição moral: "cuidado com os ambíguos".

Estas criaturas, expatriadas de seus verdadeiros sexos, tomam corpo e se manifestam em imagens cercadas de misticismos e alertas. São as figuras menino-menina que despertam tanto medos quanto desejos. Uma intensa produção discursiva procura apreendê-las, colocá-las sob um manto de verdades únicas e consoantes, para, então, naturalizá-las e enquadrá-las nas noções de normalidade. Mas os corpos e desejos ambíguos são amplamente dissonantes, escapando e vazando, daqui e dali, num fluxo que foge e faz fugir às normas que buscam regê-los.

Este texto se destina a seguir, ainda que precariamente, ao encontro destas figuras fluidas, das pessoas andróginas, hermafroditas, bissexuais. Nossa intenção, apesar disso, não é lidar com as características anatômicas que tornam um corpo intersexo, nem tampouco definir os desejos e as estilísticas singulares que fazem com que alguém seja considerado bissexual. Tratase, antes, da aproximação com linhas de desejo e de intensidade que ultrapassam e borram as fronteiras delimitadas para a diferença sexual. Para nós, o que está em jogo é, antes de tudo, o nomadismo. A criatura bissexual seria aquela que se desloca, que não é nem de um lugar nem 
de outro, e que não pertence nem a este mundo nem àquele. Talvez seja aí que resida sua força política e contestadora: em sua ambivalência e em seu movimento, naquilo que ela possui de monstruoso e assustador.

Essa operação, que tende a extrapolar o conceito de bissexualidade, nos foi apresentada pela revista Anything That Moves: Beyond the Myths of Bisexuality (ATM), publicada entre 1990 e 2002 nos Estados Unidos da América. A bissexualidade é mostrada pela revista ATM como algo indeterminado e contrário a posições estáticas. Tudo se move, e a noção de bissexualidade faz parte desse movimento. No manifesto editorial da revista, não há uma definição precisa para a bissexualidade ou para o que é ser bissexual, nem mesmo uma representação universal que englobe cada um e cada uma com uma sexualidade fluida. Nele se destaca, antes, a perspectiva de dialogar com os diversos significados do termo bissexualidade e, também, com os limites impostos por meio dessas definições.

Não espere que essa revista seja representativa para todas as pessoas bissexuais, pois nossa diversidade é muito vasta. Não espere que um corte preciso para a definição de bissexualidade salte dessas páginas. Nós, bissexuais, tendemos a definir a bissexualidade de maneiras que são exclusivas a nossa própria individualidade. Existem tantas definições de bissexualidade quanto há bissexuais. Muitos de nós escolhemos não nos rotularmos de maneira alguma, e consideramos que a palavra 'bissexual' pode ser inadequada ou muito limitadora. Não assuma que as opiniões expressas aqui são compartilhadas por todos os bissexuais, por aqueles envolvidos ativamente no Movimento Bissexual ou pelo pessoal da ATM. [...] Essa revista é sobre Qualquer Coisa Que Se Mova: aquilo que nos move a pensar; que nos move a foder (ou não); que nos move a sentir; que nos move a acreditarmos em nós mesmos (ANYTHING THAT MOVES, 2017, tradução nossa).

O alvo de nosso interesse é, portanto, a multiplicidade que enuncia o nós bissexual como instância altamente arriscada e precária, tendo em vista as possibilidades que transbordam ao conceito de bissexualidade e ressaltam pontos de resistência e desorientação que tensionam, a partir de dentro, as normas do sistema sexo/gênero.

Para seguir tais desvios e incongruências, optamos por realizar uma abordagem genealógica. Tendo no horizonte a intuição de Gilles Deleuze e Félix Guattari (1997) quanto aos procedimentos das ciências nômades, consideramos a genealogia como uma ciência em movimento, que trata de acompanhar as singularidades como quem segue os sulcos escavados no escoamento da água. A genealogia se constitui nesse desvio esculpido pelo fluxo da água, tal qual a semente ali se instala, fazendo nascer outra planta e expandindo seu território num continuum variável. O objetivo de uma genealogia é, desta forma, pôr as variáveis em estado 
de transformação perpétua, captando ou determinando as singularidades dos fenômenos - em vez de extrair deles uma forma exclusiva, única ou, ainda, suas origens remotas.

Para Deleuze e Guattari (1997), com a genealogia não se representa - um povo, uma classe ou uma minoria qualquer -, mas, antes, engendra-se e percorre-se. Trata-se de colocar cada coisa, inclusive o próprio sujeito, em um estado de variação não-fundacional, agitando o que pensamos ser imóvel e fragmentando as unificações. Conforme indica Foucault (2005), o alvo do procedimento genealógico é aquilo que passa por não ter história alguma, como, por exemplo, o sexo e a natureza humana. Por isso, a genealogia tende a ultrapassar qualquer possibilidade de formalização ou sintetização em um método exclusivo, procedendo, primeiramente, a partir da invenção de problemas. Afinal, se o poder opera de forma binária com os sexos, gêneros e as sexualidades, resta-nos a possibilidade de impor-lhe problemas, que lhe são inevitáveis. Como aponta Judith Butler (2015), a nossa incumbência é descobrir a melhor maneira de criar problemas ao poder, a melhor maneira de tê-los.

Neste sentido, nos propomos a tecer esse texto a partir de um duplo objetivo. Utilizando as proposições de Judith Butler acerca da noção de abjeto, bem como as de Jorge Leite Júnior e Michel Foucault sobre a categoria de monstro, buscaremos deslindar a trama discursiva que elaborou a diferença sexual unívoca como parâmetro para o verdadeiro, tornando-a condição primária para a construção de sujeitos e para a classificação dos corpos e existências segundo um critério diferencial de humanidade. Para isso, nos concentraremos, a princípio, em algumas das maneiras pelas quais o discurso sobre o hermafrodita foi sendo modificado ao longo dos séculos XVIII e XIX na Europa, resultando na concepção de que existe uma impossibilidade de dois sexos estarem presentes em um único corpo.

Em um segundo momento, realizaremos um encontro genealógico com o manuscrito "Minhas Memórias", escrito por Herculine Barbin, no século XIX, bem como com outros documentos agrupados no livro Herculine Barbin: o diário de um hermafrodita, publicado por Foucault em 1978. Com Herculine seguiremos linhas fugidias e movimentos cambaleantes, que vazam das fronteiras bem marcadas do sistema sexo/gênero. Nosso objetivo é pensar, em conjunto com Herculine, a ambivalência sexual - seja ela a bissexualidade, o hermafroditismo ou a androginia - como trouble maker ${ }^{2}$, realçando suas potencialidades para causar problemas às normas que gerenciam a diferença sexual binária. Em nosso encontro com essa instigante personagem, será possível nos depararmos com o assombroso e tocar as zonas inóspitas da 
abjeção, territórios quase ininteligíveis, mas que, ao mesmo tempo, tornam compreensível a moderna concepção de humano.

\section{As ambivalências sexuais e os impasses de um ser impossível}

Segundo Valerio Marchetti (2001), do século XVII até pelo menos o final do século XIX europeu, os termos bissexual e hermafrodita eram correlatos. Elisabeth Sarah Lewis (2012: 26) indica que a utilização da palavra bissexual para nomear os corpos dos hermafroditas era comum especialmente nos campos da medicina, do direito e da teologia, nos quais "diversos discursos se entrelaçavam para construir a pessoa fisicamente bissexual como um terceiro sexo sujeito a uma série de restrições jurídicas”. Até o princípio do século XIX, o termo andrógino também era considerado como sinônimo de hermafrodita. Já as denominações intersexual e intersexo apareceram em 1917, e passaram a ser utilizadas, mais amplamente, na segunda metade do século XX - quando o termo hermafrodita perdeu grande parte de sua força referencial, ao menos para o discurso científico (LEITE JÚNIOR, 2011). Não obstante, esses termos remetiam, portanto, à justaposição dos sexos em um único corpo e à composição de uma alma, ao mesmo tempo feminina e masculina, em um único indivíduo.

Com esse brevíssimo histórico, pretendemos destacar que as palavras bissexual, andrógino, intersexual e hermafrodita guardam algumas relações entre si. Todas elas, de algum modo, tendem a se referir aos seres nos quais sexos e identidades se misturam. No entanto, há uma série de mudanças no discurso científico por meio das quais o hermafrodita e o andrógino, ou seja, o corpo bissexual da Antiguidade e da Idade Média europeias foi se transformando no pseudo-hermafrodita da modernidade. Nesse momento, faremos uma pequena genealogia dos corpos ditos monstruosos e de sua conexão com as misturas entre os sexos, explicitando alguns procedimentos a partir dos quais o discurso científico da modernidade proclamou a inexistência do hermafrodita. No percurso, encontraremos pelo caminho o descendente mais direto do hermafrodita que, longe do que poderia parecer, não é o intersexual da atualidade, mas sim o anormal.

Michel Foucault (1982) indica que a possibilidade de sobreposição dos sexos num só corpo parecia ser relativamente bem-aceita durante o século XIX. Prova disso era o status jurídico e legal conferido aos hermafroditas. Até esse século, as regras do direito - canônico ou civil - definiam como hermafroditas as pessoas nas quais os sexos se justapunham. "Nesse caso, era papel do pai ou do padrinho (os que 'nomeavam' a criança) fixar, no momento do batismo, 
o sexo que deveria ser mantido" (FOUCAULT, 1982: 1). Quando essa criança chegasse à vida adulta e quisesse se casar, poderia escolher permanecer com aquele sexo que lhe havia sido atribuído ou, caso desejasse, assumir outro sexo. Uma vez feita essa escolha, porém, ela não poderia ser desfeita, sob a pena de o indivíduo ser considerado sodomita e julgado segundo os rigores da lei. Para Foucault (1982: 2) eram, justamente, "essas mudanças de opção e não a mistura anatômica dos sexos que engendravam a maior parte das condenações dos hermafroditas".

Apesar de serem raros, há casos de condenação de hermafroditas por serem hermafroditas até, pelo menos, o final do século XVI europeu. Foucault (2010) cita o caso de Antide Colas. Em 1599, Colas foi denunciado por ser hermafrodita e queimado vivo depois de um exame médico concluir que, de fato, ele possuía os dois sexos e que a única explicação possível era a de que deveria ter tido relações com Satanás. Após ser torturado, Colas confessou ter tido sexo com Satanás, seu corpo foi queimado e suas cinzas espalhadas ao vento. Todavia, no século XVIII apareceu uma jurisprudência diferente e casos como os de Colas passaram a ser tratados com menos misticismo. Um hermafrodita já não era mais condenado apenas por ser hermafrodita, mas sim nos casos em que ele usasse o seu sexo suplementar, em que decidisse se vestir com as roupas do sexo oposto ou, ainda, caso mantivesse relações com uma pessoa do mesmo sexo que seu sexo dominante. No século XVIII, o que passou a ser considerado abominável no hermafrodita foi, dessa forma, esse transitar entre roupas, comportamentos e papéis sociais, misturando-os; embaralhando e confundindo as noções do que era considerado ser homem ou ser mulher. Assim, as punições legais destinadas aos sujeitos incertos não tinham mais como alvo, em primeiro plano ou exclusivamente, o corpo cujo órgão genital era ambíguo, mas os deslocamentos sistemáticos entre um sexo e outro.

Segundo Foucault (2010), do século XVII ao final do século XVIII, incidirão sobre o corpo do hermafrodita, de maneira mais aguda, as instâncias de saber e de poder. É em torno desses seres dúbios que se começa a elaborar uma nova conformação do monstruoso. O monstro hermafrodita vai constituir, para a lei, um problema duplo: jurídico e natural. Isso porque, de um lado ele é, em si mesmo, a encarnação de algo contrário à natureza, ele é propriamente o abominável. De outro, o hermafrodita gera um embaraço legal: afinal, se um indivíduo possui dois sexos, não se sabe se ele deve ser "tratado como menino ou como menina; se se deve ou não autorizá-lo a se casar e com quem; se pode ser titular de benefícios eclesiásticos; se pode receber as ordens religiosas, etc." (FOUCAULT, 2010: 56). 
A monstruosidade, como afirma Foucault (2010), até o final do século XVIII europeu, era, essencialmente, uma noção jurídico-biológica, ligada à mistura (entre humano e animal, os dois sexos, a vida e a morte ou entre os diferentes reinos). O que definia o monstro era, a priori, o fato de ele constituir, "em sua existência mesma e em sua forma, não apenas uma violação das leis da sociedade, mas uma violação das leis da natureza" (FOUCAULT, 2010: 47). O monstro contradizia a lei, levando a infração ao seu ponto máximo. Mas, apesar de levar ao limite a infração das leis, o monstro não deflagra, por parte da lei, uma resposta direta. $\mathrm{O}$ monstro engana e transgride a lei; entretanto, a resposta para sua existência vem na forma da violência, da adequação ou do cuidado médico. Isso não significa que o hermafrodita estivesse fora da lei ou, ainda, que fosse inalcançável pelas leis. Tratava-se, antes, de uma situação na qual as leis naturais, sociais e divinas eram colocadas em suspensão; de eventos nos quais as regras do direito, seja canônico ou civil, tinham de lidar com suas inconsistências, com suas margens. O monstro era, ao mesmo tempo, uma infração à ordem natural e, além disso, um enigma jurídico. Uma mistura perigosa entre os sexos ou entre os reinos, sem dúvida, mas, sobretudo, entre o impossível e o proibido. Nesse ponto de encontro, entre a antinatureza e o ininteligível, residia o entendimento da monstruosidade e, portanto, sua ligação com o corpo do hermafrodita.

Ao longo do século XIX europeu, tanto o hermafroditismo quanto a diferença sexual em si começariam a ser pensados de um modo diferente. Conforme indica Foucault (2010: 61), no desfecho do século XVIII, "no discurso médico, o hermafroditismo não é mais definido [...] como um misto dos dois sexos”. Para os médicos da época já não havia mistura ou presença simultânea dos sexos num só organismo e num só indivíduo. O que existia eram apenas indivíduos com seu verdadeiro sexo, ou seja, com o seu sexo predominante, e com outro sexo que, no entanto, é suplementar e mal formado. "E, por conseguinte, o que se chama de hermafroditismo não passa de uma má conformação acompanhada de uma impotência" (FOUCAULT, 2010: 62). Em outras palavras, o hermafrodita se torna o impasse de um ser impossível (LEITE JÚNIOR, 2011).

Durante o século XIX, essa concepção jurídica e científica - de que não existe algo como um hermafrodita - vai se tornar cada vez mais presente. A junção dos sexos em um mesmo corpo, a ambivalência dos genitais, a possibilidade de uma alma ambígua seriam, paulatinamente, substituídas pela impraticabilidade de um corpo bissexual. O chamado hermafrodita completo é tomado como nada mais que uma farsa, um erro da natureza que o 
olhar clínico do médico trata de desvendar. Nascia, dessa maneira, o conceito de pseudohermafrodita, junto com uma nova forma de pensar a ambivalência sexual. Forjada pelas ciências sexuais modernas, a ideia de que há uma disparidade elementar entre os sexos e a impossibilidade de sua coexistência num único indivíduo inseriu o bissexual, o andrógino e o hermafrodita na grande e confusa família dos anormais (LEITE JÚNIOR, 2011).

Não por acaso a figura do monstro hermafrodita vai perdendo força no século XIX. A partir desse século, forma-se toda uma nova economia do poder, que ascende junto com as disciplinas e a biopolítica modernas. Nesse processo, a figura mítica do monstro vai ser substituída por outra, mais discreta e menos carregada. Se nos séculos precedentes era em torno do "monstro humano" que os poderes e saberes se organizavam, no século XIX se testemunha a ascensão de uma figura mais indiferente aos poderes, que expressava, em si mesma, a universalização dos desvios sexuais e a generalidade das pequenas patologias presentes em todos os indivíduos (FOUCAULT, 2010). No século XIX, o corpo anormal encobre o corpo monstruoso. Trata-se do nascimento ou, melhor, da emergência de um outro regime de verdades sobre os corpos. Como afirma Leite Júnior (2011), não haverá mais lugar nas ciências para alguém com os dois sexos, apenas para pessoas com um verdadeiro sexo e seu gênero correspondente. Assim, a noção de que os indivíduos são dotados de um verdadeiro sexo e da distinção sexual como elemento imutável se constitui como um aparato indispensável ao exercício do poder.

Se, até o início do século XIX, havia alguma liberdade de escolha para os indivíduos incertos, a emergência de dispositivos de poder que se desdobram no e sobre o sexo trataria de limitar esse horizonte. As teorias biológicas da sexualidade, as embrionárias concepções jurídicas sobre os indivíduos e as formas de controle próprias dos Estados modernos vão recusar a ideia de uma mistura dos sexos em um único indivíduo (FOUCAULT, 1982). A partir daí, "um só sexo para cada um. A cada um sua identidade sexual primeira, profunda, determinada e determinante" (FOUCAULT, 1982: 2). Já não se trata mais, seja na medicina ou no direito, de determinar qual sexo prevalece no hermafrodita, mas de decifrar qual o verdadeiro sexo que se esconde por trás da anatomia confusa ou do comportamento sexual ambíguo.

O papel do médico, a partir de então, será o de despir as ardilosas anatomias do corpo humano, reencontrando o único e verdadeiro sexo de cada um, para desvendar, por fim, aquilo que se oculta nos comportamentos duvidosos e nas práticas lascivas. Como indicou Foucault (1982), existe todo um interesse moral no diagnóstico clínico do verdadeiro sexo. Com ele, 
pretende-se evitar que as fantasmagorias da natureza possam servir aos abusos da libertinagem e que os indivíduos se aproveitem de certas peculiaridades anatômicas para dissimular o seu verdadeiro sexo, usando de seu corpo como se ele pertencesse ao outro sexo ou transitando entre um sexo e outro. Nesse sentido, coube à medicina - mas, também, à psicologia, à psiquiatria, às famílias e ao direito - despertar uma consciência profunda e definitiva sobre o nosso verdadeiro sexo.

Sabemos, contudo, que os campos da medicina, da psicologia e do direito são, na atualidade, mais tolerantes em relação aos sujeitos incertos e que se retrataram, mesmo que com algumas ressalvas, desse tipo de entendimento reducionista sobre o corpo e sobre as subjetividades. Ainda assim, a ideia de que cada um de nós deve ter um único e verdadeiro sexo está longe de ser desfeita. Permanecemos acreditando que entre sexo e verdade há uma relação determinante, relacionada diretamente com a morfologia do corpo, que agora é objeto da medicina. Conforme sugere Foucault (1982: 4), se durante séculos acreditamos que era preciso esconder as coisas próprias do sexo, hoje temos um imenso aparelho de verdades construído sobre a noção de verdadeiro sexo, de tal modo que admitimos que "é o próprio sexo que esconde as partes mais secretas do indivíduo: a estrutura de seus fantasmas, as raízes de seu eu, as formas de sua relação com o real. No fundo do sexo, está a verdade”. Isso, de fato, não remete apenas à descoberta do verdadeiro sexo, mas também a um processo de identificação, caracterização, classificação, ordenação e gerenciamento das perversões sexuais que, por sua vez, está amplamente conectado ao problema do indivíduo e da espécie na ordem das anomalias sexuais. Entremeado a essa concepção de anormalidade, o monstro reaparece como "o grande modelo de todas as pequenas discrepâncias" (FOUCAULT, 2010: 48).

Dos limites que ele expressa, o monstruoso - especialmente no início do século XIX europeu - vai engendrar um princípio de inteligibilidade que é, de certo modo, tautológico. $\mathrm{O}$ grande problema desse século era o das pequenas monstruosidades presentes em cada desvio, em todas as anomalias e nas mais minúsculas irregularidades. Segundo Foucault (2010: 48), é nesse sentido que essa inteligibilidade, concebida através do monstro, será tautológica, pois “é precisamente uma propriedade do monstro afirmar-se como monstro, explicar em si mesmo todos os desvios que podem derivar dele, mas ser em si mesmo ininteligível". É este princípio, ou seja, o de uma explicação que só remete a si mesma, "que vamos encontrar bem no fundo das análises da anomalia" (FOUCAULT, 2010: 48). Embora o monstro apareça, diante da lei, como algo ininteligível, como o ponto-limite de qualquer transgressão, é a ele que a lei se refere, 
é nele que ela volta, quando se trata do anormal. "É a questão, por exemplo, que Lombroso ${ }^{3}$ formulará ao lidar com os delinquentes. Qual é o grande monstro que se oculta detrás de um gatuno?” (FOUCAULT, 2010: 48). Em suma, a monstruosidade é aquilo que se esconde na essência de qualquer comportamento anormal, desviante ou mesmo criminoso. O anormal será um monstro empalidecido, mas ainda presente - pelo menos até o início do século XIX - como princípio de inteligibilidade para todos os tipos de anomalia.

Esse problema, da classificação dos corpos segundo um critério de normalidade, se conecta, abertamente, à forma como foi sistematizada a concepção de um sujeito humano, dotado de um sexo, um gênero e uma sexualidade lineares e bem definidos. Isso fica explícito, por exemplo, nas proposições de Butler $(2019,2015)$ sobre a noção de abjeto. Acompanhando as proposições de Foucault, Butler sugere o entendimento da sexualidade como uma organização histórica e específica de certos mecanismos de poder e que, efetivamente, produziu o sexo como conceito, sobretudo artificial, capaz de ampliar e mascarar as relações de poder responsáveis por sua gênese. Decorre daí que o sexo não é apenas uma característica física, a descrição de algo que alguém possui ou daquilo que alguém é. O sexo é, com efeito, uma das normas pelas quais se torna possível a existência dos sujeitos e, mais particularmente, dos sujeitos humanos.

Para Butler (2019), há uma pujante função normativa que é exercida pelos enunciados: "é um menino" ou "é uma menina". São eventos gráficos que inauguram o sexo e o gênero para cada um de nós - apesar de essa inauguração ser mais demorada para algumas pessoas, como no caso dos intersexuais. Essas atribuições são parte daquilo que alimenta os campos de discurso e de poder que orquestram, delimitam e sustentam o que é legitimamente descrito como humano, como sujeito humano; e elas o fazem a partir de uma operação diferencial. Butler afirma que o sujeito não precede e nem sucede às atribuições de gênero. Ao contrário, o sujeito emerge junto com essa matriz das próprias relações de gênero. Ao afirmar que o sujeito e o ser humano são produzidos em uma matriz generificada das relações, a autora não pretende se livrar do sujeito, mas, antes, perguntar-se sobre as suas condições de emergência e operação, bem como sobre os meios de exclusão que negam a alguns corpos e existências as possibilidades de estarem na categoria de humanidade.

Portanto, não é suficiente afirmar que os seres humanos são construções, pois a construção do humano também é uma operação diferencial que produz o mais ou menos 'humano', o inumano, o humanamente inconcebivel. Esses locais excluidos, ao se transformarem em seu exterior constitutivo, chegam a limitar o 'humano' e a assombrar tais limites, por 
representarem a possibilidade persistente de sua irrupção e de sua rearticulação (BUTLER, 2019: 23-24).

Conforme Butler (2019), os locais de inabitabilidade, aquilo que não é inteligível pela norma hegemônica de distribuição da diferença sexual, compõem o exterior constitutivo do sujeito. É a partir da negação e descarte desse exterior incategorizável, dessa zona de abjeção, que o sujeito pode se organizar em torno de uma identidade - seja ela a sexual ou a identidade humana. Assim, Butler promove uma releitura do conceito de abjeto. Tal conceito foi formulado, a princípio, por Georges Bataille, em 1957. Segundo Edson Luiz Andre de Souza e Silvia Ferreira (2010), para Bataille, o abjeto se relaciona com um sistema de violência e exclusão social no qual, paradoxalmente, ele opera como uma forma de coesão social. Aquilo que esse sistema não é capaz de assimilar, ele rejeita, num movimento que é tanto de atração quanto de repulsão do que é considerado como abjeto e, portanto, não assimilável. Em 1988, Julia Kristeva retoma o conceito de abjeto, "propondo-o como inerente ao sujeito: abjeção é aquilo que se produz de forma ameaçadora e não assimilável; algo que solicita, inquieta, fascina o desejo" (SOUZA; FERREIRA, 2010: 82).

Judith Butler - notadamente nas produções Gender Trouble: Feminism and the Subversion of Identity (1990) e Bodies that Matter (1993) - apropria-se do conceito para nomear essas zonas inóspitas e ininteligíveis que são ameaças à integridade do sujeito e, igualmente, condições primárias para sua existência. Para Butler (2019), o abjeto é aquilo que nós não queremos ser, o domínio contra o qual nós nos constituímos por medo de sermos, nós mesmos, considerados como seres abjetos. O sujeito seria formado por meio dessa força da abjeção, do rechaço e da exclusão; em suma, de forças "que produzem um exterior constitutivo para ele, um exterior abjeto que é, afinal, 'interior' ao sujeito como seu próprio repúdio fundacional" (BUTLER, 2019: 18).

O domínio do abjeto é, para Butler (2019), composto pelas zonas inabitáveis e inóspitas do sistema sexo/gênero que são, porém, densamente povoadas por corpos que não se conformam - seja em suas práticas sexuais, desejos ou anatomia - com sua regularidade. É nesse território inabitável que se localizam os não-humanos, os inumanos ou os que ainda não podem ser considerados como sujeitos humanos pelas normas hegemônicas. E aqueles que vivem sob o signo do inabitável são necessários para circunscrever o domínio do sujeito. O paradoxo que reside na noção de sujeito humano é, justamente, a necessidade de que essas zonas inóspitas existam para que ela possa ser inteligível, para que se possa operar um corte 
vertical entre o normal e o anormal, o saudável e o patológico, e assim por diante. O domínio do abjeto atua, então, como uma espécie de entidade fantasmagórica, assombrando as fronteiras do sistema sexo/gênero e do sujeito. Ele constitui uma espécie de fora sempre a ameaçar a integridade dos enquadramentos que separam os homens das mulheres, os humanos dos monstros e os normais dos anormais.

Para Butler (2015), existem corporalidades e modos de vida que destoam das pressuposições sobre os corpos sexuados, perturbando a regularidade da distinção sexual. São esses exemplos, quer dizer, os seres incoerentes, os que estão "fora da lei", enfim, os abjetos, que nos fornecem uma maneira de compreender o mundo da distinção sexual como um mundo construído, e que, sendo assim, também poderia ser construído de outras maneiras. Nesse sentido, Butler sugere que é preciso assumir uma posição conscientemente desnaturalizada para que se perceba como a naturalidade da distinção sexual é, ela mesma, construída a partir de um ato performativo que produz aquilo que nomeia. Do mesmo modo, é somente assumindo um posicionamento que também esteja fora dos termos de inteligibilidade do sujeito que podemos perceber como o sujeito humano é, ele próprio, construído. E, quando bem entendido, o termo construção não remete a uma entidade totalitária, mas sim a "um processo de reiteração através do qual emergem tanto os 'sujeitos' como seus 'atos' [...] uma atuação reiterada que se faz poder em virtude de sua persistência e instabilidade" (BUTLER, 2019: 28).

O sistema sexo/gênero é, portanto, composto por continuidades, regularidades, endurecimentos e, ao mesmo tempo, por instabilidades, desvios e fluxos que vazam de suas atribuições binárias. Para que um corpo possa ser legível nos termos desse sistema é preciso evidenciar o seu sexo, marcá-lo como verdadeiro. Em seguida, é necessário que os comportamentos sexuais e sociais (sexualidade e gênero) estejam mais ou menos de acordo com aquilo que se espera desse sexo, sobrando pouco espaço para as ambivalências e para movimentos transversais. A ambiguidade ou indefinição aparece, então, como ameaça a ser domada, de modo que os corpos sexualmente indeterminados serão, com alguma frequência, considerados monstruosos, "apenas acidentais, superficiais, ou mesmo simplesmente ilusórios" (FOUCAULT, 1982: 2). Paradoxalmente, são essas lacunas e ranhuras do sistema sexo/gênero, causadas pelos indefinidos de todos os tipos, que demonstram a potencialidade plástica e volátil da distinção sexual - e que a sistematização dos sexos trata de tentar contornar. Como afirma Paul B. Preciado (2014: 129), as conturbações, os acidentes e os desvios comportam múltiplas possibilidades para evidenciar "a construção tecnológica e teatral da verdade natural dos sexos", 
demonstrando que, mesmo quando se trata da anatomia do corpo, no sentido mais restritivo do termo, existem margens e exceções.

Segundo Preciado (2014), os critérios pelos quais se define quem é menino ou quem é menina são confusos, por exemplo, no caso das crianças intersexuais. Nesses casos, todo um aparato tecnológico de recorte do sexo precisa ser colocado em movimento para que a atribuição binária seja bem-sucedida. A mutilação genital e a intervenção hormonal, não raro, são recursos usados, desde os primeiros meses de vida da criança para que seus pais possam levar para casa uma menina ou um menino - mesmo que essa menina tenha nascido com um pequeno pênis e o menino com um clitóris gigante. Algo semelhante acontece nas cirurgias de transgenitalização, nas quais um pênis pode ser transformado em vagina, ou vice-versa. Isso indica, em primeiro plano, que a incorporação da diferença sexual se dá a partir de uma mesa de recortes, de uma série de procedimentos e de intervenções destinadas a produzir essa diferença elementar entre os sexos. Aquilo que Butler denomina ato performativo passa, assim, por operações incisivas, colocadas em ação diretamente no corpo dos indivíduos. Em segundo lugar, a necessidade de que todos os corpos passem por esses recortes, ou seja, que nenhum de nós tenha escapado aos enunciados "é um menino" ou "é uma menina”, indica a coexistência potencial de mais de um sexo num único órgão, de possibilidades tanto femininas como masculinas (ou neutras) nos sujeitos, independente de sua anatomia. Os mecanismos de atuação do sistema sexo/gênero são responsáveis por tentar barrar, gerenciar ou conter esse possível.

Acompanhando as análises de Preciado e Butler, percebemos que há a existência de um devir bissexual presente nos corpos e desejos - que, certamente, não se refere a suas características orgânicas. Há zonas inóspitas e paradoxais que atuam como fantasmas constitutivos dos sujeitos. É o domínio do abjeto. Da mesma maneira, assombrando a distinção sexual normativa está a possibilidade latente de um devir bissexual, desse vislumbre de um possível pertencimento ou mesmo de uma aproximação com o que é particular ao "outro sexo". Essa possibilidade tende a ser nublada pelos procedimentos médicos e jurídicos de distribuição da diferença sexual, constituindo um domínio de abjeção e de repúdio sem o qual o modelo de um sexo exclusivo não pode permanecer e funcionar. Esse modelo invoca, por um lado, a imagem do hermafrodita como monstruosidade, como aquilo que é incategorizável. Por outro lado, ele é dependente de sua inteligibilidade tautológica para regular o verdadeiro sexo de cada um e para traçar um corte vertical entre o normal e o anormal, entre o saudável e o patológico. 
Há, deste modo, certa potência criativa no terreno movediço da monstruosidade e da abjeção - e que a regulação normativa dos sexos procura conter. Com a intenção de realçarmos algumas dessas potencialidades, retomaremos a noção de monstro a partir da visão oferecida por Leite Júnior, atentando para suas aproximações e distanciamentos em relação ao abjeto. Depois, teremos um encontro com Herculine Barbin, intersexual que viveu e escreveu suas memórias durante o século XIX, e cuja narrativa expressa as linhas de deriva próprias a um devir bissexual.

\section{A vós a terra, a mim o espaço sem limites}

Em sua análise, Leite Júnior (2012: 560) explica que o abjeto é o “ininteligível, aquilo que, na constituição do sujeito [...] é expulso como não categorizável. $O$ abjeto é o que está fora das categorias de pensamento socialmente inteligíveis". Porém, as pessoas mais tocadas pela zona de abjeção são comumente alvo de violências, tratadas de maneira inferiorizante e, não raro, inspiram medo, confusão e perseguição. Isso talvez revele que essas pessoas "não estão além ou fora das categorias conhecidas de inteligibilidade social. Talvez elas estejam em uma outra categoria específica de inteligibilidade [...]: na categoria de 'monstros"” (LEITE JÚNIOR, 2012: 561). Embora Foucault localize o conceito de monstruosidade especificamente entre os séculos XVIII e XIX, Leite Júnior oferece outra interpretação para o termo, utilizando, para tanto, a etiologia da palavra monstro. O monstro é aquele que nos mostra algo, a manifestação física de alguma coisa qualquer além do porvir esperado, em suma, ele integra "uma tentativa inteligível de classificar e orientar condutas em relação àqueles seres e pessoas que a princípio escapam da inteligibilidade cultural do período" (LEITE JÚNIOR, 2012: 562). Os monstros são imagens ainda vivas na atualidade. Eles ocupam as mesmas zonas inóspitas que os corpos abjetos. Todavia, há uma diferença elementar entre o conceito de monstro e o de abjeto. Falta ao abjeto algo que o monstro possui em demasia: "o fascínio pela quebra das normas conhecidas, o encanto pela transgressão, a sedução pelo quase desconhecido" (LEITE JÚNIOR, 2012: 562).

Entre as criaturas monstruosas, encontramos uma personagem singular: Adèlaïde Herculine Barbin, pessoa intersexual que viveu até os 21 anos como uma moça. Ela passou sua infância num orfanato para meninas; depois, mudou-se para um convento; e, por último, tornouse professora e gestora de uma escola para moças em La Rochelle, na França. Aos 21 anos, porém, Herculine foi reconhecida como sendo um hermafrodita masculino, teve seu gênero retificado e adotou o nome Abel Herculine Barbin. Ao se tornar Abel, mudou-se para Paris, 
onde viveu seus últimos dias sob a égide de um gênero que lhe parecia de todo estranho. Após completar 30 anos, em 1868, suicidou-se, deixando, ao lado de seu corpo, o manuscrito intitulado "Minhas Memórias"4.

Escolhemos o caso de Herculine Barbin para este encontro por alguns motivos. Em primeiro lugar, a data em que ela escreveu suas memórias. Como indica Foucault (1982), o período em que Herculine viveu é um momento de intensa caça às identidades sexuais e ao verdadeiro sexo de cada um. Ao mesmo tempo, presencia-se a ascensão de outro regime de poder/saber sobre os corpos hermafroditas e sobre os incertos de todos os tipos. A autópsia de Herculine - que foi publicada no Journal de l'anatomie et la physiologie de l'homme, em 1869 - nos apresenta alguns indícios dessa nova forma de tratar o hermafroditismo. Encontramos um exemplo disso neste trecho: "desse conjunto de observações poderíamos também concluir claramente, caso fosse ainda necessário demonstrar, que o hermafroditismo não existe no homem ou nos animais superiores" (GOUJON, 1982: 128).

Em segundo lugar, o caso de Herculine é singular pela riqueza de detalhes com a qual seu corpo é descrito. Isso é, inclusive, motivo de orgulho para E. Goujon, médico-legista e autor do relatório: "A observação que vou aqui relatar é uma das mais completas que a ciência já possuiu do gênero" (GOUJON, 1982: 120). As ciências médicas trataram de traduzir, segundo suas formas específicas de inteligibilidade, os discursos que melhor explicariam os conflitos e a natureza dessa existência dúbia. E Herculine já esperava por isso.

Quando esse dia [de minha morte] chegar, alguns médicos farão tumulto em torno de meus despojos; eles virão buscar em mim nova luz, analisar todos os misteriosos sofrimentos que se concentram num único ser. Oh príncipes da ciência, sábios químicos, cujos nomes ecoam no mundo, analisem então, se for possivel, todas as dores que queimaram e devoraram esse coração até suas últimas fibras; todas as lágrimas ardentes que o inundaram, dessecaram em suas selvagens opressões! (BARBIN, 1982: 96).

Ânus, uretra, pelos, pênis, membros superiores e inferiores, protuberâncias, todas as entradas, os canais e os desvios do corpo de Herculine são descritos de forma clínica detalhada. Como indicou Foucault (2010: 60), é nesse momento que vemos aparecer, "e ao mesmo tempo se teorizar, a necessidade de um discurso científico sobre a sexualidade e, em todo caso, sobre a organização anatômica da sexualidade". O discurso médico, pelo menos até esse período, era impermeável a esse tipo de discussão. O caso de Herculine mostra que, a partir do século XIX, há uma inversão nesta lógica. É preciso descrever minuciosamente os erros e imperfeições da natureza para categorizá-las, inseri-las em uma grade de inteligibilidade e, consequentemente, gerenciá-las de maneira ótima. 
Por fim - e este é o ponto mais importante -, escolhemos o caso de Herculine porque nele não existe verdadeiro sexo. Há, antes, certa monstruosidade, uma mistura difícil de separar, um devir bissexual que a impele em direção às zonas inóspitas do abjeto. Isso fica explícito em sua autópsia, especialmente no seguinte trecho: “A conformação dos órgãos genitais externos desse indivíduo lhe permitia, embora manifestadamente fosse um homem, representar indistintamente o papel de homem ou de mulher" (GOUJON, 1982: 121).

Seu corpo é uma mescla tão intricada que foi, em certo sentido, difícil determinar a natureza de seu sexo. Primeira monstruosidade: há, no corpo de Herculine, não apenas uma mistura entre os sexos, mas uma mistura muito astuciosa. Contudo, não se trata somente das irregularidades anatômicas que, porventura, viessem a camuflar o verdadeiro sexo de Herculine. A narrativa expressa nas "Memórias" permite perceber que ela mesma não tinha uma noção definitiva sobre o sexo ao qual pertencia. Isso aparece, por exemplo, nas formas como Herculine refere-se a si mesma: meu querido/minha querida, meu doce/minha doce Camille ${ }^{5}$, ele/ela. Percebemos, em sua narrativa, que os pronomes, sejam eles femininos ou masculinos, funcionam como meros artifícios flutuantes, sempre em deslocamento. Herculine trata de inventar outros esquemas de linguagem, que já não se enquadram nos enunciados do sistema sexo/gênero.

Ao fazer com que pronomes masculinos e femininos se confundissem e se sobrepusessem ao longo da narrativa, Herculine se distanciou da rigidez dos enunciados do sistema sexo/gênero e de seus poderosos eventos gráficos - que inauguram o sexo para todos nós. Ela não é nem um menino nem uma menina. Nesse procedimento, ela nubla tanto o sujeito da enunciação quanto a matéria que ele pretende enunciar: um hermafrodita não pode enunciar seu sexo e seu sexo não pode ser enunciado. Assim, aquilo que Herculine diz de si mesma, a maneira como ela se percebe, é inominável para o sistema sexo/gênero e, igualmente, inassimilável nos termos da norma. "Ainda jovem, me enterrei viva nessa eterna solidão que encontro em todos os lugares, por entre as multidões, como no mais ignorado dos retiros" (BARBIN, 1982, p. 94). Ela é, em certo sentido, ilegível. E é dessa condição, desse limiar entre o inumano e ininteligível, que ela escreve as "Memórias". "Profundamente desgostosa de tudo e de todos, suporto, sem nenhuma emoção, as injustiças dos homens, e seus ódios hipócritas, pois não poderão jamais me atingir na fortaleza segura em que me escondo" (BARBIN, 1982: p. 95). 
Se o léxico do sistema sexo/gênero é árido, Herculine paira sobre ele. Sua escrita eclode de uma utilização puramente intensiva da linguagem, que flexiona a língua binária, falada pelo sistema sexo/gênero, para um outro uso, que é propriamente hermafrodita. Herculine fala e escreve em uma outra língua, num hermafroditês. "Alheio e sonhador, meu rosto parecia curvarse sob o peso de obscuras melancolias. Eu era fria, tímida...” (BARBIN, 1982, p. 13). Nele, pronomes femininos e masculinos trepam uns nos outros. Com esse modo subversivo de usar a linguagem - que remetemos, primeiramente, às potências do terreno inominável tocado por seus modos de vida e, também, a essa escrita hermafrodita que ela inventa -, ela anuncia, já de antemão, a inevitável falência do sistema sexo/gênero. Ele, ela, homem, mulher: cada sujeito do sistema sexo/gênero é deslocado de suas condições de enunciação. Com esse procedimento, Herculine sobrecarrega o masculino e o feminino com suas próprias penúrias, encharcando-os com uma pluralidade de sentidos conflitivos e, concomitantemente, privando-os de qualquer sentido unissonante. Sua escrita atrapalha o sistema sexo/gênero, ressalta suas contradições internas e burla seus princípios operacionais. Herculine estressa esse sistema, levando-o ao limite. E um sistema estressado tende a ficar instável, seus processos de comunicação entram em colapso, e ele se torna parcialmente inoperante quanto ao gerenciamento de suas fronteiras.

Esta é sua segunda monstruosidade: Herculine não é um homem ou uma mulher, mas alguém que permanece transitando entre os gêneros, que segue por uma movimentação - tão precária quanto constante - e por um devir bissexual que a arrasta em direção às zonas do ininteligível. "Esse resultado inevitável [...] eu já tinha previsto, e até desejado" (BARBIN, 1982: 77). Assim, ela também transparece certo desejo pelo desconhecido que, por um lado, dispara seus medos e, por outro, a impulsiona a ultrapassar os limites bem marcados do sistema sexo/gênero. "Eu era perseguida por uma ideia constante. Surgia o novo horizonte de um futuro que não podia mais ser adiado!!!” (BARBIN, 1982: 61). Terceira monstruosidade de Herculine: é uma espécie de avidez que a faz desejar a retificação de seu sexo, como ela mesma afirma na última frase das suas memórias: "Não sei que estranha cegueira me fez sustentar até o fim esse papel absurdo. Talvez tenha sido a sede do desconhecido...” (BARBIN, 1982: 105).

Como criatura monstruosa, Herculine ousa tocar essa zona para além da fronteira, esse terreno inóspito da abjeção. E, como tal, a categoria de humanidade parece não a alcançar. E isso ela também pressente, pois sabe que há, entre ela e os ditos humanos, "um abismo, uma barreira intransponível... Eu os desafio, a todos" (BARBIN, 1982: 95). A sobrecarga efetivada por sua escrita acaba curto-circuitando o sistema sexo/gênero, de modo que Herculine encontra 
certas dificuldades para estabelecer conexões. Ela emerge, então, como exemplo desses seres abjetos que não parecem estar propriamente generificados, de modo que a sua própria humanidade é questionada.

Vai, maldito, cumpre o teu destino! O mundo que invocaste não foi feito para ti. Não foste feito para ele também. Nesse vasto universo onde todas as dores têm lugar, tu procurarás em vão um canto para abrigar a tua. Mas a esse canto sua dor macularia. Ela inverte todas as leis da natureza e da humanidade (BARBIN, 1982: 92).

Como afirma Butler (2018), passar por uma privação radical de reconhecimento ameaça as possibilidades de um corpo existir e persistir. Viver nesse limite, entre o abjeto e o humano, significa que a viabilidade da vida de uma pessoa - ou de um grupo de pessoas - é colocada em questão. Mas isso indica, igualmente, a possibilidade de estarmos no limiar para desenvolver os termos que nos permitam viver uma vida de outras maneiras, quem sabe, mais democráticas para os corpos e desejos em conflito com as normas hegemônicas. Para isso, é preciso certa dose de coragem, como aquela demonstrada por Herculine.

Nas questões mais simples da vida sempre me faltaram coragem e iniciativa. Diante do perigo, entretanto, sinto-me forte. A infelicidade me enche de coragem. E foi assim que me senti naquele instante, em que estava em jogo toda a minha vida... A guerra que provavelmente ia ter que enfrentar, me dava um impulso sobrenatural (BARBIN, 1982: 74).

Da impossibilidade pulsante de seu não-lugar no mundo, desse fora que ela insiste em ocupar, Herculine fala de uma realidade que ainda não existe ou cuja possibilidade é apenas virtual. E encontrá-la poderia fazer valer a morte. "Lá está a morte, o esquecimento. Lá, sem nenhuma dúvida, o infeliz exilado do mundo encontrará finalmente uma pátria, irmãos e amigos. Lá haverá lugar para o proscrito" (BARBIN, 1982: 96). Escrever é, para Herculine, uma maneira de encontrar qualquer escapatória, de forjar uma saída através da linguagem e, quem sabe, de criar um outro mundo para seu corpo proscrito. "Não havia lugar para mim nesse mundo que me evitava e considerava maldito" (BARBIN, 1982: 13). É preciso, por meio da escrita literária, inventar um outro mundo, encontrar seu próprio território, tornar-se, de algum modo, legível e inventar novas conexões.

Como explica Butler, para aqueles que são apagados ou rebaixados pelas normas, "a luta se torna uma batalha corpórea por condição de reconhecimento, uma insistência pública em existir e ter importância” (BUTLER, 2018: 44). Quando nós aceitamos que existe um domínio da abjeção, podemos "ver como os 'ilegíveis' podem se construir como um grupo, desenvolvendo formas de se tornar legíveis uns para os outros" (BUTLER, 2018: 45). Como 
parte dos ilegíveis, essa situação fronteiriça, ocupada por Herculine, colocou-a diante da disposição para "exprimir uma outra comunidade potencial, de forjar os meios de uma outra consciência e de uma outra sensibilidade. Como o cão das Pesquisas que na sua solidão faz apelo a uma outra ciência" (DELEUZE; GUATTARI, 2003: 40).

As "Memórias" de Herculine não falam meramente de sua vida ou de sua história. Quantos de nós já não desejaram desertar o próprio gênero? E quantos de nós já não se descobriram vivendo sob a égide de um gênero que não nos pertence ou cujo sistema linguístico de binômios perfeitos nos parece árido e sem vida? Herculine vive, à sua maneira, nessa terra devastada, que é como ela mesma percebe o mundo que a cerca.

Oh! Viver só, sempre só, no meio da multidão que me cerca, sem que nenhuma palavra de amor venha me alegrar a alma, sem que uma só mão amiga venha se estender para mim! Que castigo terrivel, e inominável! Será que há alguém que possa me compreender? (BARBIN, 1982: 87).

Contudo, sua fala ecoa a voz de um território nascente que, alguns séculos depois, se transformará numa multidão de experimentadores de gênero, de criaturas cujos sexos não são um, nem dois, mas uma caldeira borbulhando as mais monstruosas misturas. Com sua escrita solitária, Herculine se funde à enunciação coletiva dos heróis de sua gente, desses proscritos da espécie humana, dos anormais, dessas monstruosas e diabólicas existências.

Como no conto "A muralha da China", de Franz Kafka, o corpo nômade de Herculine já era, desde o princípio, um invasor dos muros descontínuos que segregam o feminino do masculino. As cidades atuais também são atravessadas por corpos que imprimem em si um nomadismo de gênero, sexualidades transviadas e fluidas, que se constroem para além dos estreitos binarismos do sistema sexo/gênero. Bissexuais, intersexuais, transviados, travestis, caminhoneiras, viados, hetero-flexíveis, bi-curiosos, não-binários, ladys, fanchas, boycetas e bixas. São existências que se recompõem e se transformam individual e coletivamente, ocupando esquinas e avenidas: elas estão lá, mas também não estão; são ameaças e são ameaçados; são, enfim, uma infinidade de territórios subjetivos e corporalidades com as quais a norma precisa lidar.

Se seguirmos a intuição de Butler (2018), deveríamos considerar tais ameaças e abjeções não como simples questionamento das convenções sociais, condenando-as ao pathos do fracasso, mas as tomar como um recurso crítico para a rearticulação dos termos nos quais os corpos são ou não tornados inteligíveis. Se os poderes contemporâneos nos oferecem, como sinônimo de normalidade e de humanidade, o terreno árido da distinção sexual e suas regulações 
normativas, talvez seja preciso responder-lhes com um bater de asas, uma fuga, uma deserção ou um movimento nômade. Nas palavras de Herculine:

Guardai pois vossa piedade. Ela vos pertence, mais do que a mim. Minha natureza angelical paira sobre todas as vossas inomináveis misérias, pois me disseste que não há lugar para mim em sua estreita esfera. A vós a terra, a mim o espaço sem limites. Acorrentados pelos laços dos vossos sentidos grosseiros, vossos espíritos não podem mergulhar no límpido mar do infinito, onde minha alma, em desvario por sobre vossas praias áridas, sacia a sua sede (BARBIN, 1982: 93).

\section{Considerações finais}

Nas seções anteriores, buscamos explicitar alguns dos procedimentos que vão, ao longo dos séculos XVIII e XIX, constituir o sujeito e a noção de humano como instâncias lineares. Para tanto, tratamos, a princípio, dos modos pelos quais os corpos dúbios, especialmente os corpos hermafroditas, foram sendo inseridos em um esquema de inteligibilidade próprio aos poderes incrustados na categoria de sexo. Também realçamos certo aspecto contraditório das normas.

Seguindo as indicações de Butler (2018: 46), assumimos que, se as normas são responsáveis por gerir e efetuar uma divisão entre os humanos e os inumanos, os normais e os anormais, é preciso admitir que elas também falham no controle que exercem, "operando mais como uma polícia ausente ou falível do que como poderes totalitários efetivos". Em certo sentido, sua atuação é, igualmente, constante e precária, pontual e relaxada, uma ação que se dá pelo tempo, mas que o próprio tempo pode modificar.

Dos limiares das categorias normativas, outras possibilidades de viver uma vida se insurgem, como no caso de Herculine Barbin, que ousou existir nesse limbo profano onde não havia verdadeiro sexo. Decerto, esse devir bissexual, essa existência entre um gênero e outro ou entre um gênero e nenhum outro - será realocada na esquematização maior do poder. Para sair do limbo da não-identidade será preciso reterritorializar esse corpo dúbio pela adequação ao masculino. $\mathrm{O}$ verdadeiro sexo, do qual ela havia sido privada, carecia de restituição. Eis o exorcismo que o sistema sexo/gênero operou em Herculine: a reestruturação de sua existência diabólica em um único e, sobretudo, verdadeiro sexo, tornando-a apreensível e inteligível em seus sacralizados esquemas de decodificação corporal. Contudo, essa contenção do nomadismo de Herculine se concretiza numa sentença cuja contradição é inevitável: ela é um homem.

O que se insinua na narrativa de Herculine é inseparável dos atuais dilemas quanto à natureza dos sexos e do desejo sexual. Em nossas sociedades "exige-se uma correspondência rigorosa entre o sexo anatômico, o sexo jurídico e o sexo social: esses sexos devem coincidir e 
nos colocam em uma das duas colunas da sociedade" (FOUCAULT, 2014: 86). Entretanto, como pondera Foucault (2014), é realmente possível sustentar que cada um de nós tenha um verdadeiro sexo e que o problema do desejo esteja imediatamente relacionado ao pretenso pertencimento a esse sexo, quando existem prazeres e anatomias conflitantes? Como enunciar a veracidade de um determinado sexo quando ele está oculto por uma irregularidade anatômica? Esses são os problemas levantados por casos como os de Herculine e pelas ambivalências sexuais de modo mais geral. Nosso compromisso foi levar esses problemas a um limiar no qual essa categoria de sexo, enquanto alicerce da construção do sujeito, pudesse ser, de certo modo, dessacralizada.

Conforme indica Butler (2018: 49), tratar criticamente a construção do sujeito é assumir uma posição fora de seus termos, destacando formas de sociabilidade e modos de "interdependência que não se reduza às formas humanas de vida e que não possa ser adequadamente referida por nenhuma definição obrigatória da natureza humana ou do indivíduo humano”. Afinal, como vimos, há modos não-humanos de vida e de corporificação, dos quais o humano, enquanto categoria ontológica, é dependente. Todavia, isso não significa retirar os monstros de sua inteligibilidade própria - apaziguando seus devires -, para tratá-los como pertencentes à espécie humana. O procedimento precisa ser outro. Antes, necessitamos, como nos indica pontualmente Leite Júnior (2012: 667), repensar os limites do que chamamos de sujeito humano, remodelando aquilo que "fica em seu exterior incategorizável (o abjeto) e, principalmente, desenvolver uma nova postura com relação ao que classificamos como monstros". Nosso medo e nosso ódio aos monstros foram historicamente criados e, da mesma maneira que foram criados, eles também podem ser desfeitos (LEITE JÚNIOR, 2012).

\section{Referências}

ANYTHING THAT MOVES: Beyond the Myths of Bisexuality - San Francisco: Bay Area Bissexual Network, 1990-2002. http://atm.silmemar.org/, acessado em 25 de abril de 2017.

BARBIN, A. Herculine. "Minhas Memórias". Em: FOUCAULT, Michel (org.). Herculine Barbin: o diário de um hermafrodita. Rio de Janeiro: Francisco Alves, 1983.

BUTLER, Judith. Problemas de gênero: feminismo e subversão da identidade. Rio de Janeiro: Civilização Brasileira, 2015.

BUTLER, Judith. Corpos em aliança e a politica das ruas: notas para uma teoria performativa de assembleia. Rio de Janeiro: Civilização Brasileira, 2018. 
BUTLER, Judith. Corpos que importam: os limites discursivos do 'sexo'. São Paulo: n-1 edições, 2019.

DELEUZE, Gilles; GUATTARI, Félix. Mil Platôs: capitalismo e esquizofrenia, vol. 5. São Paulo: Ed. 34, 1997.

DELEUZE, Gilles; GUATTARI, Félix. Kafka: por uma literatura menor. Lisboa: Assírio \& Alvim, 2003.

FOUCAULT, Michel (org.). Herculine Barbin: o diário de um hermafrodita. Rio de Janeiro: Francisco Alves, 1982.

FOUCAULT, Michel. Nietzsche, a genealogia, a história. Em: Ditos \& Escritos II: arqueologia das ciências e história dos sistemas de pensamento. Rio de Janeiro: Forense Universitária, 2005.

FOUCAULT, Michel. Os anormais: curso do Collège de France (1974-1975). São Paulo: Martins Fontes, 2010.

FOUCAULT, Michel. O misterioso hermafrodita. Em: Ditos \& Escritos IX: genealogia da ética, subjetividade e sexualidade. Rio de Janeiro: Forense Universitária, 2014.

GOUJON, E. Estudo de um caso de hermafroditismo imperfeito no homem. Em: FOUCAULT, Michel (org.). Herculine Barbin: o diário de um hermafrodita. Rio de Janeiro: Francisco Alves, 1983.

LEITE JÚNIOR, Jorge. Nossos corpos também mudam: a invenção das categorias "travesti" e "transexual” no discurso científico. São Paulo: Annablume, FAPESP, 2011.

LEITE JÚNIOR, Jorge. Transitar para onde? Monstruosidade, (des)patologização, (in)segurança social e identidades transgêneras. Revista Estudos Feministas, vol. 11, $\mathrm{n}^{\mathrm{o}}$ 20, 2012.

LEWIS, Elizabeth Sara. "Não é uma fase”: construções identitárias em narrativas de ativistas LGBT que se identificam como bissexuais. 2012. Dissertação de Mestrado. Programa de Pós-Graduação em Literatura, Cultura e Contemporaneidade, Pontifícia Universidade Católica do Rio de Janeiro, RJ, 2012.

MARCHETTI, Valerio. L'invenzione della bisessualità: discussioni trateologi, medici e giuristi del XVII secolo sull'ambiguità dei corpi edelle anime. Milão: Bruno Mondadori, 2001.

PRECIADO, Paul B. Manifesto Contrassexual: práticas subversivas de identidade sexual. São Paulo: n-1 edições, 2014.

SOUZA, Edson Luiz Andre; FERREIRA, Silvia. Marcas do abjeto na arte contemporânea. Revista Tempo Psicanalítico, Rio de Janeiro, vol. 42, nº 1, 2010.

Izabel Rizzi Mação

Doutoranda pelo Programa de Pós-Graduação em História da Universidade Federal do Espírito Santo (PPGHis/UFES) e bolsista da Fundação de Amparo à Pesquisa e Inovação do

Espírito Santo (FAPES).

Integrante do Grupo de Estudos e Pesquisas em Sexualidades (GEPSs) e do Laboratório de Teoria da História e História da Historiografia (LETHIS), ambos da Universidade Federal do

Espírito Santo (Ufes). 
Davis Moreira Alvim

Doutor em filosofia pela Pontifícia Universidade Católica de São Paulo (PUC/SP). Professor do Instituto Federal de Educação, Ciência e Tecnologia do Espírito Santo (Ifes), professor do Programa de Pós-Graduação em Ensino de Humanidades do Instituto Federal do Espírito Santo (PPGEH/Ifes) e do Programa de Pós-Graduação em Psicologia Institucional da Universidade Federal do Espírito Santo (PPGPsi/Ufes). Professor do ensino médio no Instituto Federal do Espírito Santo (Ifes). Integrante do Grupo de Estudos e Pesquisas em Sexualidades (GEPSs) da Universidade Federal do Espírito Santo (Ufes).

E-mail: davis.alvim@ifes.edu.br

\title{
Julio César Bentivoglio
}

Doutor em História pela Universidade de São Paulo (USP) e pós-doutor em História pela Universidade do Estado do Rio de Janeiro (UERJ). Professor do Departamento de História da Universidade Federal do Espírito Santo (Ufes). Professor do Programa de Pós-Graduação em História e do Programa de Pós-Graduação em Geografia, ambos da Universidade Federal do Espírito Santo (PPGHis/Ufes; PPGG/Ufes). Coordenador do Laboratório de Estudos em Teoria da História e História da Historiografia

(LETHIS-UFES).

E-mail: juliobentivoglio@gmail.com

\begin{abstract}
1 O termo "hermafrodita", atualmente, é considerado ofensivo e caiu em desuso - ao menos no contexto da autodenominação. Esse termo aparece em nosso texto devido a sua utilização em algumas fontes e, também, por causa de nosso compromisso com as ambivalências sexuais, com os modos por meio dos quais elas foram sendo pensadas, sistematizadas e apreendidas ao longo da história. No entanto, é importante salientar que, quando se trata de pessoas cujo corpo não se ajusta àquilo que foi naturalizado como feminino ou masculino, a palavra "intersexual" é mais apropriada e representativa. Para mais informações sobre o tema, ver: AYUSO, Barbara. "Sou intersexual, não hermafrodita": as pessoas que não se encaixam na atribuição tradicional do sexo pedem maior visibilidade, sem clichês ou desinformação. Disponível em: http://bit.ly/3cT7HTn, acessado em 12 de março de 2020.

2 Encrenqueira, causadora de problemas

3 Foucault se refere ao trabalho do antropólogo criminal Cesare Lombroso, concentrado, especialmente, no estudo das diferentes essências da delinquência. Para mais informações, ver: LOMBROSO, Cesare. L'uomo delinquente studiato in rapporto all'antropologia, alla medicina legale ed alle discipline carcerarie. Milão, 1876 [trad. bras. O homem delinquente. Porto Alegre: Lenz, 2001].
\end{abstract}

4 As memórias de Adèlaïde (Abel) Herculine Barbin foram encontradas no quarto onde ela residia, no bairro de Odéon, Paris, no mês de fevereiro de 1868. Elas foram publicadas, apenas parcialmente, por Auguste Ambroise Tardieu, em 1874, em Question médico-legale de l'identité' dans ses rapports avec les vices de conformation des organes sexuels. Tardieu descartou de sua publicação grande parte do que se referia à vida de Herculine como Abel. Essas partes do texto nunca foram recuperadas. O "Minhas Memórias" foi republicado por Michel Foucault, em 1978, na obra Herculine Barbin: o diário de um hermafrodita, em conjunto com notas da imprensa, certidões, autópsias, contos e mais uma série de documentos sobre o caso. 
5 "Camille" é um pseudônimo que Herculine utiliza para falar de si mesma. É interessante notar que, na França, o nome pode servir para homens e mulheres. Vemos um exemplo disso na fala do médico que atesta a condição intersexual de Herculine: “"Francamente', me disse o bom doutor, 'sua madrinha foi muito feliz na escolha do nome Camille"” (BARBIN, 1983: 76). 